\title{
APOSTILLAS SAHAGUNTINAS
}

\author{
Leonor Bonilla \\ Universidad Santo Tomás
}

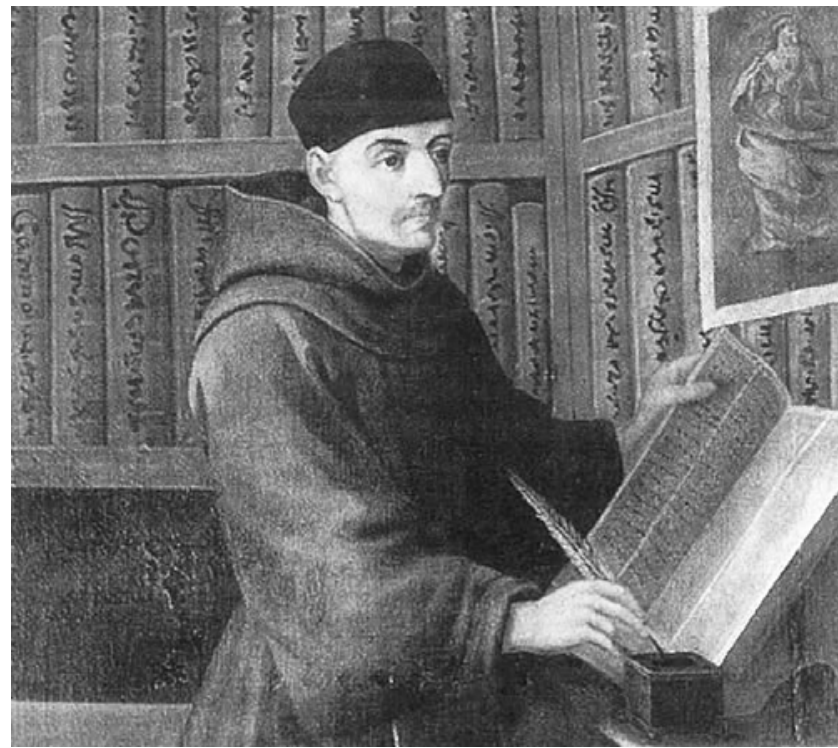

\section{Resumen}

En el año de 1529 desembarcó en el puerto de Veracruz Fray Bernardino de Sahagún, quien habría de convertirse en el gran investigador de la cultura nahua. Consciente de que el trabajo misional de los padres franciscanos, que lo habían precedido, no había producido los resultados esperados por la falta de conocimiento de los pueblos aborígenes, decidió aprender la lengua nahuatl; preparó, de entre los naturales, a sus futuros colaboradores y comenzó la obra que iba a tener tres frentes: el evangelizador, el lingüístico y el histórico-étnico-cultural. Posteriormente, elaboró un cuestionario fundamental para ser contestado por los «principales ancianos» de cada localidad y, por último, realizó la recopilación de toda la información. Gracias al empeño de este gran franciscano que supo superar muchos obstáculos para la terminación de su obra, se logró la reconstrucción del mundo mexicano en ese gran libro titulado Historia general de las cosas de Nueva España. 


\section{Palabras clave}

Bernardino de Sahagún, México, cultura nahua, siglo XVI.

\section{Abstract}

Fray Bernardino de Sahún, landed at Veracruz harbor in 1529 and would become later on the great researcher of nahua Culture. He was aware that the missionary work of his predecessors, hadn't brought about the expected results, mainly due to the lack of knowledge about those native towns. Therefore, he first of all decided to learn the nahuatl language; he trained among native people, the ones who were going to be his co-workers and in this way, he began his work based on three branches: gospeling, linguism and cultural - ethnic- historic. Later on, he made a basic questionnaire to be answered by the local wise men, the elder ones and lastly, he compilled all the information. Thanks to the engagement (endeavor) or this great francis priest, who learned how to overcome so many obstacles, in order to fulfill his work, he could rebuild (makeover) the mexican world in that great book whose title is "general history of new things in New Spain".

\section{Index terms}

Bernardino de Sahagún, México, Nahúa Culture, XVI Century.

Cuando Oswald Spengler, el controvertido historiador alemán, agrupa y comenta las más importantes culturas de la antigüedad en su Decadencia de Occidente, al referirse a los aztecas dice:

Porque esta cultura es el único ejemplo de una muerte violenta. No falleció por decaimiento, no fue ni estorbada ni reprimida en su desarrollo. Murió asesinada en la plenitud de su evolución, destruida como una flor que un transeúnte decapita con su vara... Se hizo imposible para siempre un conocimiento cierto del mundo mejicano, aún en los rasgos más generales de su historia ${ }^{1}$.

Sobre la primera parte de esta cita se pondrían muy pocos reparos u objeciones, pero, sobre la segunda parte, surgen muchas reservas, justificadas por posteriores descubrimientos, estudios e investigaciones, porque "ese conocimiento del mundo" mejicano pudo ser reconstruido para la posteridad por una esclarecida y providencial personalidad: fray Bernardino de Sahagún.

La celebración, en la pasada década, del quinto centenario no sólo del nacimiento de este ilustre franciscano, sino también de lo que el sistema historiográfico iberoamericano llamó, eufemísticamente, "encuentro de dos culturas" (léase descubrimiento de América), originó múltiples reediciones de la obra sahaguntina, basadas en los diferentes códices existentes. Igualmente, dichos eventos dieron ocasión a la publicación de magistrales escritos sobre la vida y los trabajos de

$1 \quad$ SPENGLER, Oswald. La decadencia de Occidente. Vol. 2. Madrid: Espasa-Calpe, 1958. 2 vol., pp. 58-59. 
Sahagún, los que proporcionaron más luces y elementos de juicio para poder justipreciar la monumental y singular contribución que este fraile hizo a la historia del México precolombino. Cabe destacar dentro de estos escritos tanto el de Miguel León-Portilla, como también el conjunto de diez ensayos, editado por Ascensión Hernández de LeónPortilla, los que traeremos a colación más adelante.

Pero estos textos sólo constituyen la culminación de un largo proceso de estudio y del consiguiente reconocimiento del valor de las obras de fray Bernardino de Sahagún, que se inició casi inmediatamente después de su muerte por cronistas como fray Jerónimo de Mendieta, fray Juan de Torquemada, el doctor Francisco Hernandez, el renombrado protomédico de Felipe II, y Domingo Chimalpahin Cuauhtlehuanitzin, entre otros.

La segunda mitad del siglo XIX fue testigo de un "renacimiento mexicanista", del que hizo esencial parte el interés por el conocimiento del pasado indígena, movimiento espiritual del que hicieron parte José Fernando Ramírez, Joaquín García Icazbalceta, Manuel Orozco y Berra y Francisco Pimentel, cuyas obras tuvieron como centro gravitacional la Historia general de las cosas de Nueva España, cuya primera edición se realizó entre 1829 y 1830.

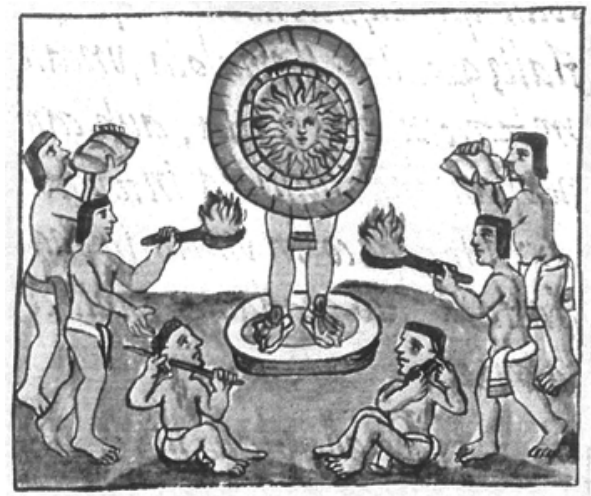

A mediados del siglo pasado, y gracias a los esfuerzos de una nueva generación de investigadores, como Wigberto Jiménez Moreno, Miguel Acosta Saignes y Angel María Garibay, se establecen nuevos puntos de referencia sobre la génesis, la cronología y la metodología de la obra de Sahagún, donde se hace hincapié en aspectos como el etnográfico y el antropológico. Es decir, ya se comienza a concretar la multifacética personalidad del corpus histórico de este eximio franciscano, el que debemos, sin alguna duda, afrontar de una manera integral, valorando equitativamente sus componentes históricos, lingüísticos, religiosos, y los etnográficos y antropológicos, ya mencionados.

Consignadas estas consideraciones preliminares, ya es tiempo de hacer una sucinta relación de una fascinante y afortunada aventura que comenzó en 1529, cuando fray Bernardino de Sahagún se embarcó en Sanlúcar de Barrameda rumbo a Nueva España, sin más equipaje que el bagaje humanístico adquirido en la Universidad de Salamanca y el firme propósito de evangelizar a los nuevos súbditos de Carlos V. Este viaje lo hizo en compañía de algunos miembros de la antigua nobleza mexicana, entre ellos dos de Moctezuma que Hernán Cortés había llevado a España, y que ya hablaban castellano. Con ellos Sahagún tuvo contacto con un nuevo mundo que, como lo veremos, terminaría "conquistándole". Esta aventura finalizó en 1590, cuando falleció, legándole a México, a América y al mundo, en general, una ejemplar y edificante obra.

En el mismo año de 1529 fray Bernardino llegó al puerto de Veracruz, en compañía de otros diecinueve franciscanos, con el ánimo de reforzar y continuar la labor evangelizadora de los "nueve millones" de indígenas, emprendida pocos años antes por los famosos "doce" sacerdotes de la misma 
comunidad, la que se había emprendido con el apoyo del mencionado emperador y del papa Adriano VI.

Tanto Sahagún como sus congéneres eran conscientes de que el trabajo misional realizado por los “doce” no había producido los resultados esperados porque había sucedido algo similar a lo que ocurrió con muchos de los judeoespañoles conversos: los aborígenes novohispanos, que aparentemente habían sido evangelizados, continuaron practicando sus viejas creencias en su vida privada.

Esta adversa circunstancia obligó a los franciscanos a replantear su estrategia misional para convertir verdaderamente a esos millones de almas, y es precisamente aquí donde fray Bernardino de Sahagún comienza a desempeñar un papel protagónico en todo este proceso. Al respecto, Josefina García Quintana y Alfredo López Austin, en su prólogo a la primera versión del texto castellano de la Historia general de las cosas de Nueva España, según el Códice Florentino, apuntan:

Además, Sahagún percibió una notoria falla en toda la empresa: el desconocimiento de las costumbres de los indios, de sus creencias, de su lenguaje, por lo que casi desde su llegada comenzó a estudiar la lengua náhuatl al tiempo que cumplía con sus deberes misionales en el convento de Tlatelolco... Se hacía necesaria una revisión de los métodos hasta entonces empleados. En consecuencia se dio mayor impulso al estudio de la lengua y a la indagación de las antigüedades indígenas ${ }^{2}$.
O mejor, como el propio Sahagún lo registró, refiriéndose específicamente a la persistencia de los cultos idolátricos:

Para predicar contra estas cosas, y aun para saber si las hay, menester es de saber cómo las usaban en tiempos de su idolatría, que por falta de no saber esto en nuestra presencia hacen muchas cosas idolátricas sin que lo entendamos ${ }^{3}$.

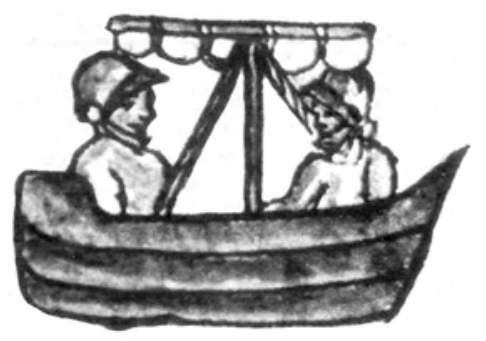

Sentadas estas premisas fundamentales, ya es tiempo de proceder a realizar una memoria de la gestación y realización de la monumental obra de fray Bernardino, así sea somera y panorámica; la que tuvo, como lo reseña Miguel León-Portilla, “tres frentes”: la evangelizadora, la lingüística y la históricoétnico-cultural. Para tal efecto, tendremos como marco de referencia formal el recorrido local-temporal que nuestro personaje hizo en la Nueva España, el cual, grosso modo, sería: Tlamanalco (1530-1533), Xochimilco (1533-1536), Tlatelolco (1536-1540), Huexotzinco (1540-1545), Tlatelolco (15451558), Tepepulco (1558-1561), Tlatelolco (1561-1565), México (1565-1568) y Tlatelolco (1568-1590).

No sobra advertir al lector que Sahagún ya había sido antecedido en el desarrollo de estas tareas por fray Toribio de Benanvente, o

2 SAHAGÚN, Bernardino de. Historia general de las cosas de Nueva España. Edición e introducción de Josefina García Quintana y Alfredo López Austin. Vol. 1. México: Consejo Nacional para la Cultura y las Artes/Alianza Editorial Mexicana, 1989, p. 14.

3 Ibíd., p. 31. 
Motolinía, y por fray Andrés de Olmos, quienes hicieron parte del mencionado grupo de los “doce”. Este último, como culminación de sus investigaciones lingüísticas, religiosas e históricas, ya había escrito su Arte para aprender la lengua mexicana, como también ya había traducido al castellano algunos Huehuetlatolli, o Huehuehtlahtolli, según deletrean otros. Más adelante hablaremos del significado de esta palabra. Motolonía, a su turno, también había realizado labores similares, pero desde un punto de vista totalmente diferente: si fray Andrés de Olmos había hecho sus estudios con respeto, cuando no admiración por todo lo relacionado con el pasado mexicano, Motolinía, como también fray Jerónimo de Mendieta, veían en su "religión y otras instituciones indígenas la obra del demonio"4, para citar a Miguel LeónPortilla en Los antiguos mejicanos. Fray Bernardino, casi sobra decirlo, optó por la directriz trazada por fray Andrés de Olmos.

Tampoco sobra advertir, para posteriores efectos y no para incurrir en apologías, que fray Bernardino de Sahagún era, antes que cualquier cosa, miembro de una comunidad religiosa profundamente arraigada en la Edad Media y que él, en ese momento, tenía como dictado prioritario la evangelización de los "nueve millones" de aborígenes y la conservación de la ortodoxia. Por tanto, no debe sorprendernos que Sahagún, en algún momento de su vida, hubiese participado en un proceso inquisitorial en el que se condenó a la hoguera, por herejía, a un prominente miembro de la nobleza del antiguo México.

La magnífica biografía de Sahagún, escrita por Miguel León-Portilla ${ }^{5}$, nos exime de detallar algunos de sus primeros movimientos por la Nueva España. Bástenos decir que Sahagún, durante su paso por Tlalmanalco y
Xochimilco, durante los ya reseñados años, ya había coleccionado algunas impresiones sobre el paisaje mexicano, como también ya había traducido algunos sermones dominicales al náhuatl.

Pero, para alcanzar plenamente las metas que nos hemos propuesto en estas notas, debemos trasladarnos a Tlatelolco, es decir, a la primera permanencia de fray Bernardino en esta localidad, entre 1546 y 1550, a donde arribó relevado de sus labores misionales. Su llegada a este lugar coincide con un hecho supremamente importante: la fundación del Colegio de Santa Cruz de Tlatelolco, donde Sahagún inicia una nueva etapa de su vida, como educador.

El establecimiento de este ente educativo hacía parte del nuevo esquema evangelizador, implementado para educar a “jóvenes indígenas, hijos de los señores principales, y escogidos por su talento" ${ }^{6}$, como lo apunta Miguel León-Portilla. Como podemos observar, los franciscanos obraban con un criterio claramente elitista.

En el Colegio de Santa Cruz de Tlatelolco se dieron clases de retórica, lógica, filosofía, gramática, latín, historia, humanidades y otras materias, y en su cuerpo docente se contó con el concurso de fray Juan Fucher y fray Juan de Gaona, asociados a la Sorbona; fray Andrés de Olmos, ya mencionado; fray Arnaldo Bassacio y fray Bernardino de Sahagún, quien se desempeñó en la cátedra de latín. Esta nómina basta para no poner en duda la excelsa calidad académica de este centro pedagógico.

Nos detuvimos aquí porque la fundación del mencionado colegio constituyó, a nuestro parecer, la primera fase del ambicioso pro-

\footnotetext{
LEÓN-PORTILLA, Miguel. Los antiguos mexicanos. México: Fondo de Cultura Económica, 1970, p. 11. LEÓN-PORTILLA, Miguel. Bernardino de Sahagún. Madrid: Historia 16/ Quórum, 1987.

6 Ibíd., p. 52.
} 
yecto sahaguntino, porque este claustro fue el semillero de donde salieron los futuros colaboradores de Sahagún, quien los denominaba cariñosamente sus "trilingües", porque hablaban latín, castellano y, obviamente, náhuatl, aludiendo a sus homónimos salmantinos que dominaban el griego, el latín y el hebreo.

En 1540 le encomiendan a Sahagún una nueva labor misional en la región de Huexotzinco (Puebla), donde continúa sus estudios e investigaciones lingüísticas e históricas del antiguo México. En esta localidad, y esto es muy importante, comparte su trabajo y sus aficiones con fray Francisco de Toral, quien, poco después, es designado como provincial del Santo Evangelio de México. Es razonable suponer que Toral no solamente hace retornar a fray Bernardino a Tlatelolco, en 1545, sino que también le encarga la recopilación de sus trabajos. El propio Sahagún nos lo dice:

Por mandato del muy reverendo padre, fray Francisco de Toral, provincial desta provincia del Santo Evangelio, y después obispo de Campeche y Yucatán, escribí doce libros de las cosas divinas o, mejor idolátricas y humanas, y naturales desta Nueva España...?.

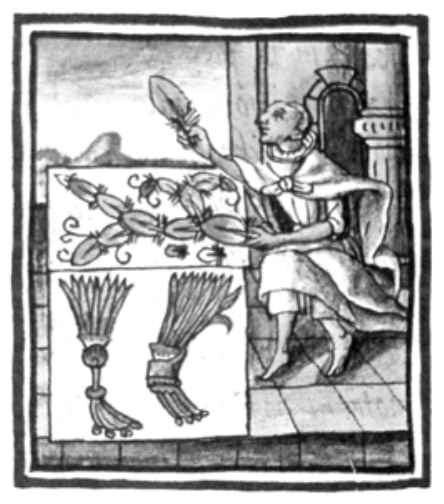

En esta segunda estadía en Tlatelolco (15451558) fray Bernardino percibe que sus aventajados "trilingües" ya estaban suficientemente preparados para asistirle en la ingente labor que le esperaba; y aquí empieza lo que consideraremos la segunda fase del proyecto sahaguntino: la elaboración de un cuestionario básico y trascendental o "minuta", como él lo llamó, para poder interrogar a los viejos sobrevivientes de la guerra de la Conquista. Sahagún, citado por Miguel LeónPortilla, la justificó así:

Recibido este mandamiento, hice en lengua castellana una minuta o memoria de todas las materias de que había de tratar, que fue lo que está escripto en los doce libros, y la postilla y cánticos...8.

Sobre esta “minuta” Miguel León-Portilla es más explícito, porque en Los antiguos mejicanos acota lo siguiente:

Tratando de penetrar en la conciencia indígena, redactó una "minuta" o cuestionario de todos los puntos que le interesaba investigar. En él se incluían entre otros los siguientes temas: ritos, sacerdotes y dioses, fiestas y costumbres, los cielos, la cuenta de los años, el más allá, cosas humanas, parentescos, costumbres de los señores, oficios, insignias, leyendas, educación y crianza, moral sexual, astrología, artesanía, sabios, ideas filosóficas, derecho, medicina, alimentación, botánica, animales, metales y piedras preciosas, orígenes étnicos, literatura, proverbios y refranes, discursos morales y teológicos, himnos y cantares y hasta una versión netamente indígena de la historia de la Conquista9.

En otras palabras, la "minuta" abarcaba casi todas "las cosas divinas o, mejor idolátricas,

\footnotetext{
Ibíd., p. 32.

Ibíd., p. 77.

LEÓN- PORTILLA, Miguel. Los antiguos mexicanos. México: Fondo de Cultura Económica, 1970, p. 73.
} 
y humanas, y naturales desta Nueva España”, frase de Sahagún que repetiremos en este escrito.

Superada esta segunda etapa de su plan, Sahagún entra de lleno a la tercera y culminante fase: "la investigación de campo", como la llama Miguel León-Portilla, es decir, la recolección y recopilación de toda la información posible, basada en la mencionada "minuta”, y contando con la colaboración de sus “trilingües, o "gramáticos”, o "latinos”. Para tal efecto, fray Bernardino recorre un periplo cuyos puntos de referencia locales y temporales son Tepepulco (15681561), Tlatelolco nuevamente (1561-1565), y México (1565-1568).

Sus primeras actividades en Tepepulco son relacionadas en el prólogo al libro II de la Historia general de las cosas de Nueva España, la que en adelante abreviaremos Historia general. Sobre estas ocupaciones Sahagún anotaba:

Hízose desta manera: en el dicho pueblo hice juntar todos los principales con el señor del pueblo, que se llamaba don Diego de Mendoza, hombre anciano, de gran marco y habilidad, muy esperimentado en todas las cosas curiales, bélicas y políticas, y aun idolátricas. Habiéndolos juntado, propúseles lo que pretendía hacer, y pedíles me diesen personas hábiles y esperimentadas con quien pudiese platicar y me supiesen dar razón de lo que los preguntase. Ellos me respondieron que se hablarían cerca de lo propuesto, y que otro día me responderían, y ansí se despidieron de mí. Otro día vinieron el señor con los principales $\mathrm{y}$ hecho un muy solenne parlamento, como ellos entonces le usaban hacer, señaláronme hasta diez o doce principa- les ancianos, y dixéronme que con aquellos podía comunicar y que ellos me darían razón de todo lo que les preguntase. Estaban también allí hasta cuatro latinos, a los cuales yo pocos años antes había enseñado la gramática en el Colegio de Santa Cruz en el Tlatilulco. Con estos principales y gramáticos, también principales, platiqué muchos días, cerca de dos años, siguiendo la orden de la minuta que yo tenía hecha. Todas las cosas que conferimos me las dieron por pinturas, que aquélla era la escriptura que ellos antiguamente usaban, y los gramáticos las declararon en su lengua, escribiendo la declaratión al pie de la pintura. Tengo aun agora estos originales... Escribiéronlos los latinos en el mismo pueblo de Tepepulco $^{10}$.

Esta cita la hacemos de la Historia general, editada (1989) por los ya mentados Josefina García Quintana y Alfredo López Austin, y basada en el Códice Florentino.

Terminado el período de provincial de Toral, fray Bernardino es trasladado por tercera vez a Tlateloco, pero esta vez se le asigna como centro de operaciones el convento de Santiago y no el Colegio de Santa Cruz. Al respecto Sahagún prosigue, anotándonos:

Cuando al capítulo donde cumplió su hebdómada el padre fray Francisco Toral, el cual me impuso esta carga, me mudaron de Tepepulco, llevando todas mis escrituras, fui a morar a Sanctiago de Tlatelulco, donde juntando los principales los propuse el negotio de mis escrituras y los demandé me señalasen algunos principales hábiles con quien examinase y platicase las escripturas que de Tepepulco traía escriptas. El gobernador con los alcaldes me señalaron hasta ocho

10 SAHAGÚN, Bernardino de. Op. Cit., pp. 77-78. 
o diez principales escogidos entre todos, muy hábiles en su lengua y en las cosas de sus antiguallas, con los cuales y con cuatro o cinco colegiales trilingües, por espacio de un año y algo más, encerrados en el Colegio, se emendó, declaró y añadió todo lo que de Tepepulco truxe escripto, y todo se tornó a escribir de nuevo, de ruin letra, porque se escribió con mucha priesa. En este escrutinio o examen el que más trabaxó de todos los colegiales fue Martín Jacobita, que entonces era rector del Colegio, vecino de Tlatilulco, del barrio de Sancta Ana ${ }^{11}$.

Son admirables la claridad y la objetividad de fray Bernardino al reseñar su paso por estas poblaciones, circunstancia que hace totalmente prescindible la ayuda de cualquier glosador, por erudito que sea.

Arribando a la última etapa de este periplo, Sahagún viaja a la ciudad de México, y en tal sentido continúa diciéndonos.

Habiendo hecho lo dicho en el Tlatilulco, vine a morar a Sanct Francisco de México, con todas mis escripturas, donde por espacio de tres años pasé y repasé a mis solas todas mis escripturas, y las torné a enmendar y dividílas por libros, en doce libros, y cada libro por capítulos, y algunos libros por capítulos y párrafos. Después desto, siendo provincial el padre fray Miguel de Navarro y guardián del Convento de México el padre fray Diego de Mendoza, con su favor se sacaron en blanco, de buena letra, todos los doce libros, y se emendó y sacó en blanco la postilla y los cantares, y se hizo un arte de la lengua mexicana con un vocabulario apéndiz, y los mexicanos emendaron y añadieron muchas cosas a los doce li- bros cuando se iba sacando en blanco, de manera que el primer cedazo por donde mis obras se cernieron fueron los de Tepepulco; el segundo, los de Tlatilulco; el tercero, los de México, y en todos estos escrutinios hubo gramáticos colegiales ${ }^{12}$.

Estos últimos párrafos son muy importantes porque describen lo que los eruditos sahaguntinos llaman el "triple cedazo", recurso del que se valió fray Bernardino para depurar su obra sobre "las cosas divinas o, mejor idolátricas, y humanas, y naturales desta Nueva España”.

Terminado este proceso, con su metodología sui generis, y dejando en claro que toda la información procesada fue transcrita al náhuatl, y que solamente unas escasas glosas fueron escritas en español, seguidamente trataremos de averiguar cómo la Historia general pudo llegar a nuestras manos.

Como en algún párrafo anterior advertimos que procuraríamos no incurrir en apologías, es necesario apelar a los embarazosos oficios de un "abogado del diablo". Para tal efecto recurriremos al ponderado criterio del tan citado Miguel León-Portilla. En la entrega número 14 de la revista La aventura de la historia, este erudito investigador mexicano, cuando se refería a los reparos y objeciones que se podrían hacer a la obra sahaguntina, afirmaba lo siguiente:

La otra objeción, vinculada a la anterior, ha consistido en preguntarse si no ocurrió acaso que los indios, percatados de los propósitos inquisidores del escudriñador de idolatrías, optaron por engañarlo en sus respuestas, malguiándolo en sus pesquisas, de suerte que lo

Ibíd., p. 32.

Ibíd., pp. 78-79. 
que creyó haber descubierto estaba muy alejado de la propia realidad cultural. En el acercamiento a lo que he llamado "su gran proyecto de investigación integral” es necesario tomar en cuenta estas objeciones $^{13}$.

Cualquier labor conducente a establecer la génesis de la Historia general nos lleva inexorablemente a realizar el mismo recorrido que ya reseñamos, y que está enmarcado en el triángulo Tepepulco-Tlatelolco-Méjico.

Cuando Sahagún llegó a Tepepulco (1558) para desarrollar la primera etapa del "triple cedazo”, ya llevaba en su equipaje, entre otras cosas, una profusa colección de Huehuehtlahtolli, o testimonios de la Antigua palabra, y una narrativa totalmente indígena de la Conquista. Los Huehuehtlahtolli eran textos de índole moral, religiosa o filosófica que los antiguos mexicanos invocaban en ocasiones específicas, que constituyen, en conjunto, una clara manifestación de su Weltanschauung.

Pero es toda la información lograda en Tepepulco la que, según los eruditos sahagunenses, conforma el núcleo primigenio, si bien esquemático y corto, pero muy bien ilustrado, de la Historia general. Este primer formato de la obra estaba constituido por tres secciones, correspondiendo cada una a "las cosas divinas, humanas y naturales", respectivamente. Hoy infortunadamente sólo se conservan las dos primeras secciones, desconociéndose el destino de la dedicada a "las cosas naturales”. Esta primera presentación de la Historia general es conocida en el mundo sahaguntino como Primeros memoriales.
En Tlatelolco (1561), fray Bernardino inicia su tarea de análisis comparativo, depuradora, pero altamente enriquecedora, y el fruto de los testimonios allí recogidos es un texto mucho más extenso y trascendental que el de Tepepulco, en el que ya aparece el capítulo atinente a "las cosas naturales".

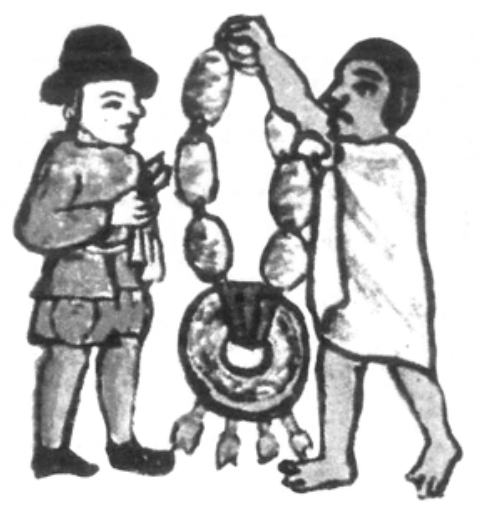

Este manuscrito quedó dividido en dos partes que, por hallarse en Madrid, son conocidas como Códice Matritense del Real Palacio y Códice Matritense de la Real Academia. El infatigable historiador Fernando del Paso y Troncoso bautizó a este manuscrito Segundos memoriales. No está de más traer a colación la reflexión que Josefina García Quintana y Alfredo López Austin hacen sobre ellos:

Es la aproximación mayor al texto náhuatl de la obra culminante, pese a que se trata todavía de un borrador sobre el que se corrigió con frecuencia. No hay aún versión al español ni lo ilustran dibujos. Sobre él se modificaron encabezados para la estructuración definitiva de capítulos y párrafos ${ }^{14}$.

13 LEÓN-PORTILLA, Miguel. “Sahagún: la fascinación por el Otro”. En: La aventura de la historia, No 14, dic. 1999, p. 64.

14 SAHAGÚN, Bernardino de. Op. Cit., p. 17. 
Como ya lo dijimos, Sahagún se traslada al Convento de San Francisco de México, donde logra la versión definitiva y organizada de la Historia general. Y fue así como de un modesto formato de cuatro libros, pergeñados en Tepepulco, se llegó a la alegórica cifra de doce, no sobrando consignar que en México, Sahagún incluyó en el corpus los comentados Huehuehtlahtolli, en el Libro VI; y la ya mencionada versión indígena de la Conquista, llamada por Miguel León-Portilla Visión de los vencidos, como el Libro XII de la obra. Este erudito historiador nos brinda una ejemplar síntesis de esta, por muchas razones, monumental obra:

La temática de cada libro es la siguiente: I. Los dioses adorados por los mexicanos; II. De las fiestas y sacrificios a los dioses en cada veintena de días con la transcripción de veinte antiguos himnos sacros; III. Relaciones acerca del origen de los dioses y en particular acerca de Tezcatlipoca y Quetzalcóatl, con apéndices sobres los destinos después de la muerte y, menos estructurados, sobre la educación; IV. Libro del tonalpohualli o cuenta de los 260 días; V. Augurios y abusiones; VI. Libro de los huehuehtlahtolli, o testimonio de la Antigua palabra; VII. El sol, la luna, las estrellas y la atadura de los años; VIII. De los reyes y nobles y de las formas de su gobierno, elecciones y maneras de vivir; IX. De los mercaderes, oficiales de oro y piedras preciosas y de trabajos de arte plumario; X. De los vicios y virtudes de la gente y de las partes del cuerpo humano, sus enfermedades y medicinas, con un último capítulo acerca de las naciones que a esta tierra han venido a poblar.
XI. De las cosas naturales, animales, árboles, plantas, metales y diversas piedras; XII. El libro de la conquista de México ${ }^{15}$.

Mas aquí no termina el proyecto sahaguntino de hacer llegar su libro hasta nuestras manos. Siglos debimos esperar para darnos este privilegio intelectual.

Es razonable suponer que fray Bernardino, con la intención de traducir al castellano, como también de hacer publicar la Historia general, propuso a sus superiores que la obra fuese escrutada bajo el punto de vista de la fe (1569). El concepto de los censores fue favorable, pero en lo relacionado con los fondos necesarios para sufragar los gastos inherentes a la empresa, el propio Sahagún nos cuenta en el prólogo al Libro II:

Algunos definidores les pareció que era contra la pobreza gastar dineros en escribiese [sic] aquellas escrituras, y ansí mandaron al autor que despidiese a los escribanos y que él solo escribiese de su mano lo que quisiese en ellas; el cual era mayor de setenta años y por temblor de la mano no puede escrebir nada, ni se pudo alcanzar dispensación deste mandamiento, estuvieron las escrituras sin hacer nada en ellas más de cinco años ${ }^{16}$.

Esta mezquina actitud de los "definidores" tenía un inconfundible sabor de retaliación. "Tal vez -opinan García Quintana y López Austin- parte de la culpa de las críticas personales a fray Bernardino haya sido de él mismo, ya que no había tenido suficiente delicadeza al hablar en sus escritos de la obra de los primeros misioneros, especialmente de Motolinía”"17.

15 LEÓN-PORTILLA, Miguel. Bernardino de Sahagún. Madrid: Historia 16/Quórum, 1987, p. 107.

16 SAHAGÚN, Bernardino de. Op. Cit., p. 79.

17 Ibíd., p. 18. 
También por esos tiempos comenzaron a aparecer malos signos para fray Bernardino porque fray Miguel de Navarro, su amigo y protector, fue relevado del cargo de provincial, y se nombró para tal oficio a fray Alfonso de Escalona, quien ordenó a Sahagún que le entregara sus escritos, los que fueron diseminados por todo México. "La intención -opina Miguel León-Portilla- era tal vez doble. Por una parte, se buscaban nuevos juicios que podrían esperarse serían adversos en contra de esos libros en los que se preservaban tantas cosas idolátricas. Por otra, cabía pensar en que, al dispersarlos, sería difícil que su autor volviera a recobrarlos en su totalidad y, en consecuencia, desistiera ya de ponerlos en castellano" ${ }^{18}$. Sahagún, consciente del destino que le esperaba a su obra y con la clara intención de recabar la simpatía y el apoyo de las altas instancias gubernamentales y eclesiásticas, y aprovechando que fray Miguel de Navarro y fray Jerónimo de Mendieta viajaban a Europa, concretamente a Italia, para asistir al capítulo general de la Orden Franciscana, decide redactar dos resúmenes de la Historia general: el primero, llamado Sumario, iba dirigido a don Juan de Ovando, presidente del Consejo de Indias, y el segundo, denominado Compendio, tenía como destinatario al Pontífice, Pío V. Del primero sabemos que llegó a las manos del importante funcionario español, quien falleció poco después. Del segundo opina irónicamente Miguel León-Portilla que “el Compendio destinado a Pío V se conserva hasta el presente en el Archivo Secreto del Vaticano... no se sabe qué es lo que expresó Pío V, si es que algo llegó a manifestar sobre el trabajo”19. El Sumario, en cambio, se extravió.

La dispersión de sus escritos trajo como consecuencia que algunos inescrupulosos se hubieran apropiado de partes de su obra, como, entre otros, se dice que lo hizo el mencionado Francisco Hernández, cuando escribió su célebre Historia natural de Nueva España.

Alrededor de 1575 comienzan a soplar vientos favorables para Sahagún. En este año llega a México fray Rodrigo de Sequera, comisario general de los franciscanos, quien es precedido por fray Miguel de Navarro. Sobre el cambio de los acontecimientos el mismo fray Bernardino nos dice:

Después de algunos años, volviendo de capítulo general el padre fray Miguel Navarro, el cual vino por comisario destas partes, en censuras tornó a recoger los dichos libros a petición del autor, y desque estuvieron recogidos, dahí a un año poco más o menos, vinieron a poder del autor. En este tiempo ninguna cosa se hizo con ellos, ni hubo quien favoreciese para acabarse de traducir al romance, hasta que el padre comisario general fray Rodrigo de Sequera vino a estas partes y los vio, y se contentó mucho dellos, y mandó al dicho autor que los traduxese al romance, y proveyó de todo lo necesario para que se escribiesen de nuevo, la lengua mexicana en una coluna y el romance en la otra, para los enviar a España, porque los procuró el señor don Juan de Ovando, presidente del Consejo de Indias, porque tenía noticias destos por razón del sumario que el dicho padre fray Miguel Navarro había llevado a España, como arriba se dixo. Todo lo sobredicho hace al propósito de que se entienda que esta obra ha sido examinada y apurada por muchos, y en muchos años, y se han pasado muchos trabajos y desgracias hasta ponerla en el estado en que agora está ${ }^{20}$.

\footnotetext{
18 LEÓN-PORTILLA, Miguel. Bernardino de Sahagún, Madrid: Historia 16/Quórum, 1987, p. 111.

19 Ibíd., pp. 112-113.

20 SAHAGÚN, Bernardino de. Op. Cit., pp. 79-80.
} 
Sahagún, apoyado institucional y pecuniariamente, emprendió en 1576 la nueva tarea, en la que nuevamente contó con el invaluable concurso de sus "trilingües". Sobre el nuevo formato de la obra, y ampliando algo lo que ya nos dijo fray Bernardino, cabría decir que el texto en náhuatl se ubicaba en la "coluna" izquierda, y en la derecha su versión en castellano, la que en muchos casos no era literal sino resumida y parafrásica. El trabajo, además, fue enriquecido con ilustraciones a color, realizadas por artistas indígenas, en las que es fácilmente perceptible la influencia de la pintura del Renacimiento. "La obra terminada-nos acota Miguel León-Portilla— se encuadernó en cuatro volúmenes. Fueron éstos los que, seguramente con profunda complacencia y dando gracias a Dios, puso Sahagún en manos de su protector, el padre Rodrigo de Sequera. A él dedicó la obra en una bella inscripción latina. El padre Sequera partió con rumbo a España a principios de 1580”21. Fray Bernardino, años después, preocupado por el destino de su protector y de su Historia general, comentaba resignadamente:

Nunca me ha scripto en qué pararon aquellos libros... y no sé en cuyo poder estén agora...22.

Este manuscrito, por ser hallado en la biblioteca Médicis de Florencia, en 1793, se conoce como el célebre Códice Florentino de Sahagún. ¿Cómo llegó allí? Tal vez algún día lo sepamos.

Pero los anteriores párrafos no constituyen un convencional happy end, porque entre 1577 y 1580 el proyecto sahaguntino fue presa de las más crudas adversidades. En 1576, por ejemplo, la población mejicana fue ob- jeto de una de las más devastadoras epidemias, la que cobró la vida de muchos de los colaboradores de Sahagún. Como si esto fuera poco, en 1577, el rey Felipe II, en la real cédula del 22 de abril, ordenaba al virrey de Nueva España, don Martín Enríquez, lo siguiente:

Por algunas cartas que nos han escripto de esas provincias, habemos entendido que fray Bernardino de Sahagún, de la Orden de San Francisco, ha compuesto una Historia Universal de las cosas más señaladas de esa Nueva España, la cual es una computación muy copiosa de todos los ritos, ceremonias e idolatrías que los indios usaban en su infidelidad, repartida en doce libros y en lengua mexicana; y aunque se entiende que el celo de dicho fray Bernardino había sido bueno y con deseo que su trabajo sea de fruto, ha parecido que no conviene que este libro se imprima ni ande de ninguna manera en esas partes, por algunas causas de consideración; y así os mandamos que luego que recibáis esta nuestra cédula, con mucho cuidado y diligencia procuréis haber estos libros, y sin que de ellos quede original y traslado alguno, los enviéis a buen recaudo en la primera ocasión a nuestro Consejo de las Indias para que en él se vean; y estaréis advertido de no conseguir que, por ninguna parte, persona alguna escriba cosas que toquen a supersticiones y manera de vivir que estos indios tenían, en ninguna lengua, porque así conviene al servicio de Dios Nuestro Señor y nuestro. Fecha en Madrid, a veinte y dos de abril de mil quinientos setenta y siete. Yo el Rey. Por mandado de S. M., Antonio de Eraso ${ }^{23}$.

\footnotetext{
21 LEÓN-PORTILLA, Miguel. Bernardino de Sahagún. Madrid: Historia 16/ Quórum, 1987, p. 124.

22 Ibídem.

23 Ibíd., p. 121.
} 
¿De dónde provenía este golpe bajo, que aparentemente era el "puntillazo" para el proyecto sahaguntino? Fernando del Paso y Troncoso, en carta dirigida a Joaquín García Icazbalceta (1884), incluida por Ascensión Hernández de León-Portilla, como editora, en el libro Bernardino de Sahagún: Diez estudios acerca de su obra (1990), comenta al respecto:

Cuando el padre Sequera mandó sacar, a fines de de 1575, la nueva copia de la Historia de Sahagún que se destinaba para el presidente Ovando, ignoraba sin duda que éste había muerto poco antes... Yo explicaría la recogida de la Historia, ordenada desde España cuando la copia que se había mandado sacar todavía no estaba concluida, de cualquiera de estas dos maneras: o por una suspicacia excesiva de los sucesores de Ovando, o por una denuncia de la obra, enviada desde la Nueva España. Si la providencia fue motivada por lo primero, no puede haberse despertado la desconfianza sino por la lectura del Sumario en la parte relativa a la Conquista de México, pues a España no había ido hasta entonces otro traslado de la Historia de Sahagún. Si la denuncia partió de estas comarcas, bien pudieron hacerla los particulares que vieron acá los manuscritos, escamados por la libertad con que se hablaba de la Conquista, o tal vez los mismos religiosos de la Orden opuestos a que las idolatrías de los indios se escribiesen en su propia lengua. La recogida por causa de lo primero indicaría en el Consejo de Indias un espíritu apocado, formando contraste con las miras levantadas de su antiguo presiden- te; fácil era entonces combatir ciertas tradiciones indígenas, puesto que todavía quedaban algunos de los testigos presenciales de aquellos hechos; pretender que se sepultaran en el olvido era darles un valor que nunca debieron tener, y exponerse a que muchos les dieran crédito. Esto sucedió justamente; Torquemada las resucitó 40 años después: nadie habló ya contra ellas, y hoy forman escuela ${ }^{24}$.

Aclarado lo relacionado con el Códice Florentino y las supuestas "rocambolescas" aventuras para lograr sobrevivir, es también pertinente hablar algo sobre el Códice de Tolosa. Este manuscrito reviste capital importancia porque fue el texto que se utilizó para realizar las primeras ediciones de la Historia general. ¿Cómo llegó a la biblioteca del convento franciscano de esta localidad guipuzcoana? La prudencia aconseja que nos acojamos a la cautelosa afirmación de Josefina Quintana García y Alfredo López Austin: "Aún no está resuelta esta pregunta”25. Lo único que podríamos conjeturar con alguna seguridad es que este códice es una copia defectuosa, apresurada e incompleta del manuscrito que fray Rodrigo de Sequera llevó a España en 1580. El Códice de Tolosa también es importante porque constituyó la primera prueba de la supervivencia de la magna obra de fray Bernardino, puesto que fray Juan de San Antonio la incluyó en su Bibliotheca universal franciscana, en 1732; y Francisco Javier Clavijero, el célebre historiador jesuita, la reseña en su monumental Historia antigua de México, en $1780^{26}$.

Por todo lo expuesto en las líneas anteriores, necesariamente debemos concluir que, para todos los efectos, el Códice Florentino, com-

24 BERNAL, Ignacio. "La obra de Sahagún, otra carta inédita de Francisco del Paso y Troncoso". En: Bernardino de Sahagún: diez estudios acerca de su obra. Edición e introducción de Ascensión Hernandez de León-Portilla. México, Fondo de Cultura Económica, 1990, pp. 106-107.

25 SAHAGÚN, Bernardino de. Op. Cit., p. 25.

${ }^{26}$ CLAVIJERO, Francisco Javier. Historia antigua de México. México: Porrúa, 1991, p. XXVI. 
parado con los demás manuscritos existentes, es la fuente más fidedigna; bástenos agregar que se realizó bajo el escrutador y celoso cuidado del propio Sahagún.

Sería razonable suponer que fray Bernardino hubiese vivido sus últimos años presa de la preocupación causada por el incierto fin que el destino le hubiera deparado a sus escritos. Pero este y otros contratiempos no fueron óbice para que Sahagún, con inusitado ánimo perfeccionista, continuara investigando el pasado indígena, cuando no reelaborando los textos que ya consideraba perdidos. Fruto de este postrer esfuerzo productivo fueron el Tratado acerca del calendario, el Arte adivinatoria y una nueva versión de la historia de la Conquista. Esta época también fue testigo de la única publicación de alguna de sus obras: la Psalmodia christiana y Sermonario (1583).

El Tratado acerca del calendario era una reconstrucción de lo que fray Bernardino había escrito en Libro II de la Historia general, poniéndolo al tenor de la reciente reforma gregoriana, promulgada en 1582.

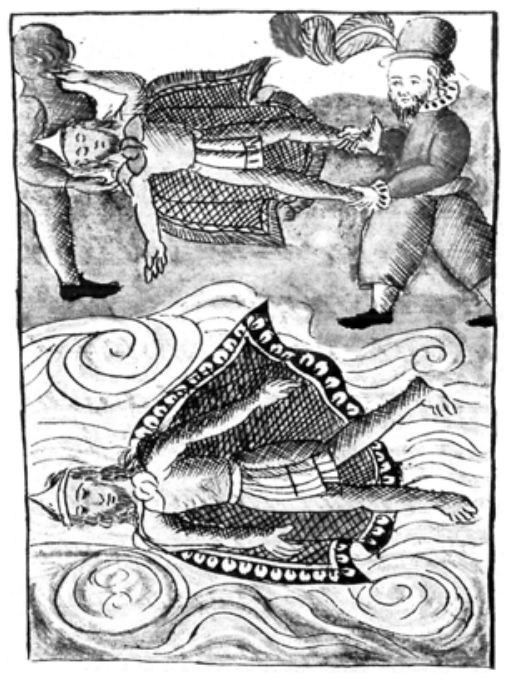

El Arte adivinatoria es una diatriba contra la idolatría y los escasos resultados que obtuvieron los primeros evangelizadores. El texto presenta analogías y similitudes con apreciables partes del Libro IV de la Historia general. Sahagún, además, nos indica que la astrología es tan vieja y ubicua como el género humano, como también obra del demonio.

Mucho más interesante bajo todo punto de vista fue la reescritura de la versión indígena de la Conquista, la "Visión de los vencidos”.

Cuando fray Bernardino redactó la primera versión de la guerra de la Conquista, a mediados de la década de los cincuentas del siglo XVI, afirmó:

Cerca desta materia allégase también a esto que los que fueron conquistados supieron y dieron relación de muchas cosas que pasaron entre ellos durante la guerra, las cuales ignoraron los que los conquistaron, por las cuales razones me parece que no ha sido trabajo superfluo el haber escrito esta historia, la cual se escribió en tiempo que eran vivos los que se hallaron en la misma conquista, y ellos dieron esta relación, personas principales y de buen juicio, y que se tiene por cierto que dixeron toda la verdad ${ }^{27}$.

¿Qué razones primaron para que fray Bernardino hubiese emprendido la reescritura de este dramático episodio treinta años después? El propio Sahagún, citado por Miguel León-Portilla, la justifica con las siguientes palabras:

...donde se trata de esta conquista, se hicieron varios defectos, y fue que algunas cosas se pusieron en la narración de esta conquista que fueron mal calladas. Por

27 LEÓN-PORTILLA, Miguel. Bernardino de Sahagún. Madrid: Historia 16/ Quórum, 1987, p. 80. 
esta causa, este año de mil quinientos ochenta y cinco enmendé este libro... va escripto en tres columnas. La primera es el lenguaje indiano, ansí tosco, como ellos lo pronunciaron y se escribió entre los libros -de la Historia general. La segunda columna es la enmienda de la primera, ansí en vocablos como en sentencias. La tercera columna está en romance, sacado según las enmiendas de la segunda columna... ${ }^{28}$.

Este formato en tres columnas nunca se encontró, sólo fue hallado un manuscrito con la tercera columna, es decir, la que solamente tiene la versión en castellano con las enmiendas y el prólogo. Este texto lo publicó Carlos María de Bustamante en 1840, quien una década antes había editado la primera impresión de la Historia general.

Nos hemos detenido en este punto por la importancia y singularidad de esta narración de la conquista de Nueva España, porque todo lo escrito hasta entonces, como también lo que se escribió después al respecto, siempre se realizó teniendo solamente en cuenta la visión triunfalista y apologética de quienes vencieron, y nunca se consideraron los testimonios y las opiniones de quienes fueron derrotados. Fray Juan de Torquemada, en su Monarquía indiana, citada por Miguel León-Portilla, no sólo concede la razón a fray Bernardino, sino que le rinde postrer reconocimiento y homenaje a su labor históricolingüístico-antropológica, cuando afirma categóricamente:

Pienso estuvo el yerro en no hacer estas inquisiciones e informaciones más que con los españoles que entonces vinieron, y no las averiguaron con los indios, que también les toca mucha parte de ellas, y aun el todo, pues fueron el blanco donde todas las cosas de la conquista se asestaron. Y son los que muy bien las supieron y las pusieron en historia a los principios, por sus figuras y caracteres y, después que supieron escribir, algunos curiosos de ellos las escribieron, las cuales tengo en mi poder, y tengo tanta envidia al lenguaje y estilo con que están escritas, que me holgare saberlas traducir en castellano con la elegancia y gracia que en su lengua mexicana se dicen...

Yo las escribiera si no las hallara averiguadas de el padre fray Bernardino de Sahagún, religioso santo y grave... El primero investigador de las cosas más secretas de la tierra, y supo todos los secretos de ella y se ocupó más de sesenta años en escribir lengua mexicana y todo lo pudo alcanzar en ella ${ }^{29}$.

Sólo nos resta hacer una última reflexión sobre esta narrativa de la conquista que, como sabemos, constituye el Libro XII de la Historia general.

No sería temerario suponer que cuando Fray Bernardino organizó esta obra, tuvo en cuenta el criterio místico-numerológico medieval al dividirla en doce libros, con la intención de rendirles una alegórica ofrenda a los Apóstoles. Además, cabría preguntarnos, y esto es más importante, ¿por qué Sahagún, al jerarquizar los temas de esta colosal Summa, en cosas divinas, humanas y naturales, obedeciendo a una clara pauta aristotélica, incluye como último segmento un relato totalmente ajeno a las directrices propuestas $\mathrm{y}$, por ende, fuera de contexto?

\footnotetext{
28 Ibíd., p. 135.

29 LEÓN-PORTILLA, Miguel. “Un testimonio de Sahagún aprovechado por Chimalpahin”. En: Bernardino de Sahagún: diez estudios acerca de su obra. Op. Cit., p. 304.
} 
Podría considerarse como prueba de lo anteriormente dicho la circunstancia de que esta historia de la Conquista se ha publicado en varias ocasiones independientemente de la Historia general, sin causar perturbación alguna. Así lo hizo Miguel León-Portilla, quien la denominó Visión de los vencidos. Este tópico, como sucede con otros tantos aspectos de la obra sahaguntina, genera más preguntas que respuestas.

Quedaría trunco este escrito si no se hiciera una reseña, así sea somera, de dos obras de fray Bernardino: la Psalmodia christiana y Sermonario y los Coloquios, textos en los que él venía trabajando desde muchos años atrás.

A la Psalmodia christiana y Sermonario sólo podemos concebirla como un experimento que Sahagún realizó en sus primeras labores misionarias, cuando trató de compaginar la praxis religiosa del México precolombino con el mensaje de las Sagradas Escrituras, sobre todo en el aspecto musical; por lo cual esta obra estaba "ordenada en cantares o Psalmos para que canten los indios en los Areytos que hacen en las Iglesias”. Después de pasar por el tamiz inquisitorial, este texto logró conseguir el imprimatur, y fue publicada, como ya lo dijimos, en 1583.

Los Colloquios y doctrina christiana con que los doze frayles de San Francisco enbiados por el papa Adriano Sesto y por el emperador Carlos quinto convirtieron a los indios de la Nueva España en lengua Mexicana y Española es el título de la otra obra de fray Bernardino, escrita en Tlatelolco, en 1564, de la cual solamente los Colloquios han llegado hasta nosotros incompletamente, porque la parte correspondiente a la doctrina christiana, como muchas de sus obras, lamentablemente se perdió.
En los Colloquios confluían las dos vertientes principales de la obra sahaguntina: la histórica y la doctrinal. Narra Sahagún en este escrito los diálogos, debates y polémicas que sostuvieron los "doce" primeros franciscanos con los sacerdotes aztecas en 1524, en los que ambos bandos expusieron la validez de sus puntos de vista religiosos, con el consecuente triunfo de los cristianos. La perfección idiomática, el dramatismo que fray Bernardino le imprime a las discusiones y el altísimo nivel académico de los argumentos, han hecho sospechoso a este escrito, porque se aduce que nuestro personaje sacrificó el rigor histórico en aras de la efectividad evangelizadora y de la elegancia literaria. Hay motivos para creer que Motolinía, quien sí fue protagonista de esta histórica confrontación, escribió algo al respecto, pero que también se perdió, desafortunadamente.

Aproximándonos al fin de los días de fray Bernardino de Sahagún, Miguel León-Portilla nos hace la siguiente síntesis:

Desenmascarar idolatrías, implantar el cristianismo, hacerlo a fondo conociendo lo secretos de la lengua en que había de predicar, y valorando lo que era la antigua cultura, esto seguía integrando el meollo mismo de las motivaciones de Bernardino. A convertir en realidad sus propósitos había dedicado ya cerca de cincuenta y seis años de su vida, desde 1529 hasta $1585^{30}$.

Fray Bernardino, en 1590, ya nonagenario, fue víctima mortal de una de las tantas epidemias que diezmaron a los mejicanos de esas épocas, y sus postreros días en Tlatelolco los narró sentidamente fray Jerónimo de Mendieta, cuando, citando por última vez a Miguel León-Portilla, registró:

30 LEÓN-PORTILLA, Miguel. Bernardino de Sahagún. Madrid: Historia 16/ Quórum, 1987, p. 137. 
...al cabo de algunos días volvió a recaer y entonces dijo: Agora sí que es llegada la hora. Y mandó traer ante sí a sus hijos, los indios que criaba en el colegio, y despidiéndose de ellos, fue llevado a México donde, acabados de recibir devotamente los sacramentos en el convento de San Francisco de la dicha ciudad, murió bienaventuradamente en el Señor y está allí enterrado ${ }^{31}$.

¿En qué puede consistir el legado que nos dejó fray Bernardino de Sahagún? En primer lugar, para orgullo de la cultura mejicana, dejó escuela, como ya lo manifestó la erudita pluma de Fernando del Paso y Troncoso en este escrito.

Hoy, por ejemplo, no podríamos concebir las obras de fray Juan de Torquemada y de fray Jerónimo de Mendieta sin los magistrales parámetros y directrices que fray Bernardino les trazó en su corpus doctrinal e histórico, especialmente los relacionados con la faceta “metodológica”, ya que sabemos que en espíritu los dos primeros miraban con recelo, cuando no satanizaban, el pasado indígena mejicano.

Tampoco hubieran sido posibles, sin el antecedente sahaguntino, los escritos del grupo de historiadores indígenas y mestizos, como Martín Jacobita, Alfonso Vegerano y Antonio Valeriano, discípulos de Sahagún; y, obviamente, las trascendentales obras de Fernando Alvarado Tezozómoc y de Domingo Chimalpahin Cuauhtlehuanitzin, para nombrar solamente a algunos.

¿Qué podríamos decir del respeto que Sahagún le profesó al indígena y a su cultura? Lamentablemente tendríamos que con- testar que en nuestro medio, quienes escribieron la protohistoria no obraron de esta manera, además que su narrativa se basó exclusivamente en la "visión de los vencedores”. En el caso de fray Pedro Simón, para escoger alguno, Juan Friede, al prologar las Noticias historiales, apunta:

Aquel primer contacto del fraile, acostumbrado a la cómoda vida en España, con las tribus primitivas del oriente venezolano, tuvo que producir un choque al recién llegado y dieron origen al menosprecio de la población indígena que ya no habría de abandonarlo. Se acrecentó incluso en 1608 con la nueva y corta experiencia (3) meses que tuvo, cuando acompañó al ejército de mando del presidente de la Real Audiencia, don Juan de Borja y conoció a los indómitos pijaos, indios igualmente "primitivos". Por otra parte, su encuentro con los muiscas de la altiplanicie chibcha, ya por entonces despojados de su manera de vivir, de su oro, mantas, etc., indios ya "miserables", no pudieron cambiar su primera impresión ${ }^{32}$.

En este sentido, y saliéndonos de la órbita historiográfica iberoamericana, vale la pena repetir lo que el eminente historiador inglés, John H. Elliot, dijo al comparar esta reprochable conducta de la gran mayoría de los misioneros con la que asumió fray Bernardino:

La aproximación de Sahagún a los indios se parecía a la de Talavera a los moros de Granada. Ambos estaban inspirados por una genuina curiosidad, por el respeto a ciertos aspectos de una civilización ajena, y por la determinación de encontrarse con los nativos en sus propios térmi-

31 DE MENDIETA, Jeronimo. Historia eclesiástica indiana. Libro V, parte I, cap. XLI. Ibíd., p. 146.

32 SIMÓN, Pedro. Noticias historiales. Vol. 1. Bogotá: Banco Popular, 1981, 6 vol. p. 23. 
nos y proporcionarles un sólido fundamento en los principios cristianos ${ }^{33}$.

Y fueron, precisamente, "esta genuina curiosidad" y este "respeto" los que hicieron que, dentro del más acendrado espíritu del humanismo español, convivieran -no diríamos que se conciliaran- el Medioevo y el Renacimiento, Europa y América, el paganismo indígena americano y el cristianismo, el náhuatl y el castellano, el Evangelio y la historia, el misionero y el educador, y otras tantas díadas más, aparentemente antitéticas, que se nos puedan ocurrir.

Esta convivencia sólo fue posible cuando Fray Bernardino se despojó, en parte, de los prejuicios religiosos y etnocentristas propios de su época, lo que tuvo como resultado una obra que, planeada originalmente para optimizar la labor evangelizadora en la Nueva España, terminara convirtiéndose en un inmenso tratado histórico, lingüístico y antropológico, honra y prez de la cultura americana; colocando, además, a Sahagún como a uno de los precursores de la mentalidad moderna.

\section{Bibliografía}

CLAVIJERO, Francisco Javier. Historia antigua de México. México: Porrúa, 1991.

ELLIOT, John H. Imperial Spain. New York: Meridian Books, 1977.

HERNÁNDEZ DE LEÓN-PORTILLA, Ascención, (ed.). Bernardino de Sahagún: diez ensayos acerca de su obra.
México: Fondo de Cultura Económica, 1990.

LEÓN-PORTILLA, Miguel. Los antiguos mexicanos. México: Fondo de Cultura Económica, 1970.

. Bernardino de Sahagún. Madrid: Historia 16/ Quórum, 1987.

"Sahagún: La fascinación por el Otro". En: La aventura de la historia (Madrid) No 14, 1999.

LÓPEZ DE GOMARA, Francisco. Historia general de las Indias. Madrid: Orbis, 1985. 2 vol.

SAHAGÚN, Bernardino de. Historia general de las cosas de Nueva España. Edición e introducción de Josefina García Quintana y Alfredo López Austin. México: Consejo Nacional para la Cultura y las Artes/ Alianza Editorial Mexicana, 1989.

SIMÓN, Pedro. Noticias historiales. Bogotá: Banco Popular, 1981. 6 vol.

SPENGLER, Oswald. La decadencia de Occidente. Madrid: Espasa Calpe, 1958, 2 vol.

TORQUEMADA, Juan de. Monarquía indiana. México: Porrúa, 1975, 3 vol.

33 ELLIOT, John H. Imperial Spain. New York: Meridian Books, 1977, pp. 70-71.* Docente de tiempo completo de la Facultad de Filosofía de la Universidad Santo Tomás, Bogotá. 